\title{
ANALISIS POSITIONING PROGRAM STUDI CREATIVE MULTIMEDIA PROFESSIONAL BERDASARKAN PERCEPTUAL MAP DENGAN METODE MULTI DIMENSIONAL SCALLING
}

\author{
${ }^{1}$ Meilana Fatharany, ${ }^{2}$ Husni Amani, ${ }^{3}$ Sari Wulandari \\ 1,2,3Program Studi Teknik Industri, Fakultas Rekayasa Industri, Telkom University \\ 1'meilanafatharany@gmail.com, ${ }^{2}$ husni.amani@gmail.com, ${ }^{3}$ sari.wulandari42@gmail.com
}

\begin{abstract}
Abstrak-Rendahnya pengetahuan masyarakat mengenai perbedaan yang dimiliki oleh Telkom Professional Certified Competency (TPCC) melalui program studinya Creative Multimedia Professional (CMP) dibandingkan dengan pesaingnya di bidang multimedia mengindikasikan bahwa TPCC belum memiliki positioning yang kuat di benak masyarakat. Tagline merupakan salah satu cara yang dapat digunakan untuk mengkomunikasikan perbedaan tersebut juga belum dimiliki oleh TPCC. Penelitian ini bertujuan untuk mengetahui positioning dari TPCC melalui program studi CMP diantara lembaga pelatihan dan sertifikasi lainnya khususnya di bidang multimedia yang berada di wilayah Bandung dan Jabodetabek. Metode yang digunakan dalam penelitian ini adalah Multi Dimensional Scalling (MDS) yang menghasilkan output berupa perceptual map. Perceptual map yang dihasilkan menggambarkan persepsi masyarakat mengenai TPCC melalui program studi CMP dengan pesaingnya bedasarkan tiga belas atribut yang ada. Hasil rekomendasi dari penelitian ini adalah keunggulan program TPCC dikomunikasikan melalui tagline, menyediakan program khusus konsultasi, melengkapi fasilitas akademik, membuat beberapa program yang dapat mengasah softskill, bekerjasama dengan perusahaan di bidang multimedia, menambah variasi kegiatan pembelajaran.
\end{abstract}

Kata kunci: Positioning, Perceptual Map, Multi Dimensional Scalling, Lembaga Pelatihan dan Sertifikasi, Persepsi Konsumen, Multimedia.

\section{PENDAHULUAN}

Masyarakat Ekonomi Asean (MEA) merupakan suatu kondisi dimana masyarakat yang berada di wilayah Asia Tenggara dapat dengan bebasnya melakukan berbagai aktivitas seperti bekerja, pembelian, penjualan, dan lain-lain tanpa harus berbatas wilayah. Kemampuan masyarakat Indonesia dituntut lebih karena mereka diharuskan untuk bersaing tidak hanya dengan orang dalam negeri melainkan dengan orang luar negeri yang berada di wilayah Asia Tenggara. Banyak dari mereka yang melengkapi kemampuan tersebut dengan mengikuti program pelatihan dan sertifikasi. Bedasarkan data yang bersumber dari BNSP [1], terjadi peningkatan jumlah lembaga sertifikasi profesi dari 19 lembaga sertifikasi profesi pada tahun 2014 menjadi 36 lembaga sertifikasi profesi pada tahun 2015.

Telkom Professional Certification Center (TPCC) merupakan salah satu badan yang bergerak di bidang pelatihan. Salah satu program yang dimiliki oleh TPCC yaitu, Certified Competency Development and Professional (CCDP). CCDP memiliki beberapa program studi. TPCC menyediakan kapasitas kelas untuk setiap program studinya sebanyak 40 orang. Sementara dari tahun 2013 sampai dengan 2015, target tersebut tidak terpenuhi untuk semua program studinya. Creative Multimedia Professional (CMP) merupakan salah satu program studi yang memiliki jumlah mahasiswa paling banyak selama tiga tahun terakhir. Namun jumlah tersebut juga mengalami penurunan tiap tahunnya.

Lembaga pelatihan dan sertifikasi yang berlokasi di Bandung dan Jabodetabek serta memiliki program studi di bidang multimedia yaitu, TPCC, Mahapatih Indonesia (Mind 8 Course), Piksi Megatama, Binus Center, Hellomotion, Internusa, Baba Studio, dan Adhibina Komputer. Dari kedelapan merek tersebut, hanya TPCC yang belum memiliki tagline. Pada penelitian ini dilakukan survei pendahuluan kepada 30 responden untuk mengetahui pengetahuan mereka mengenai perbedaan antara TPCC dengan lembaga pelatihan dan sertifikasi lainnya yang memiliki program studi di bidang multimedia. Bedasarkan survei pendahuluan tersebut dapat diketahui program studi CMP yang dimiliki oleh TPCC belum dikenal secara baik oleh masyarakat. Hal tersebut ditunjukkan dengan banyaknya responden yang memilih sama saja dan tidak mengetahui perbedaan program studi CMP dengan lembaga pelatihan dan sertifikasi lainnya yang bergerak di bidang multimedia. Perbedaan yang dimiliki oleh TPCC dibandingkan dengan kompetitornya adalah TPCC memberikan sertifikasi tingkat internasional dan juga memiliki masa studi yang paling lama dibandingkan dengan yang lain. Perbedaan yang dimiliki oleh TPCC tersebut belum diketahui oleh masyarakat.

TPCC melalui program-program studinya terbilang merek yang sudah lama berada di tengah masyarakat, sehingga perlu diketahui mengenai penilaian masyarakat terhadap TPCC 
khususnya pada program studi CMP dengan tujuan mendapatkan positioning yang tepat. Oleh karena itu, diperlukan penelitian lebih lanjut mengenai positioning dari salah satu program TPCC sendiri, yaitu CMP.

\section{STUDI LITERATUR}

\section{A. Positioning}

Menurut Kotler [2], positioning adalah tindakan merancang penawaran dan citra perusahaan agar mendapatkan tempat khusus dalam pikiran pasar sasaran tujuannya adalah menempatkan merek dalam pikiran konsumen untuk memaksimalkan manfaat potensial bagi perusahaan. Positioning merek yang baik membantu memandu strategi pemasaran dengan cara memperjelas esensi merek, tujuan apa yang dapat diraih pelanggan dengan bantuan merek, dan bagaimana merek menjalankannya secara unik.

\section{B. Multi Dimensional Scalling (MDS)}

Menurut Malhotra [3], Multi Dimensional Scalling (MDS) atau Penetapan Skala Multidimensi merupakan sebuah kelas prosedur untuk merepresentasikan persepsi dan preferensi responden secara spasial dengan menggunakan sebuah tampilan visual.

\section{Jarak Euclidean}

Pesaing terdekat dapat terlihat dari perceptual map yang dihasilkan, tetapi akan menimbulkan masalah apabila dalam perceptual map tersebut tidak terlihat perbedaan secara visual dari titik-titik koordinat yang dihasilkan. Masalah tersebut dapat diatasi dengan cara menghitung jarak euclidean/ euclidean distance untuk masing-masing merek yang dilibatkan. Semakin kecil jarak euclidean yang dihasilkan, maka semakin dekat jarak dari setiap objek dan semakin tinggi juga tingkat persaingan antar merek tersebut. Berikut ini merupakan rumus untuk menghitung jarak euclidean menurut Simamora [4].

$$
e d=\sqrt{\left(X_{i}-X_{m}\right)^{2}+\left(Y_{i}-Y_{m}\right)^{2}}
$$

\section{Penelitian Terdahulu}

Penelitian ini dilakukan dengan mengacu pada penelitian yang telah dilakukan sebelumnya oleh Mustaniroh, Mulyarto, dan Nurkhasanah [5] yang membahas positioning dari produk keripik kentang bedasarkan atribut rasa, kerenyahan, harga sesuai kualitas produk, harga terjangkau, ketersediaan produk, lokasi strategis, iklan menarik, dan iklan yang digunakan, Badrian [6] yang membahas positioning dari layanan televisi berbayar Groovia TV bedasarkan product features, tangible, reliability, responsiveness, assurance, dan empathy, Altivira [7] yang membahas positioning dari menu breakfast restoran waralaba bedasarkan kesesuaian harga, pelayanan, variasi menu, kualitas rasa, suasana, dan kebersihan. Bedasarkan ketiga penelitian terdahulu tersebut, metode yang dapat digunakan untuk meneliti positioning suatu produk atau layanan dapat menggunakan metode MDS. Perbedaan penelitian ini dengan ketiga penelitian terdahulu tersebut yaitu objek yang dikaji dalam penelitian ini adalah lembaga pelatihan dan sertifikasi serta atribut-atribut yang dilibatkan dalam penelitian.

\section{METODE PENELITIAN}

Penelitian ini diawali dengan melakukan identifikasi terhadap atribut-atribut melalui wawancara dan studi literatur pada penelitian terdahulu. Wawancara dilakukan untuk mendapatkan VoC dari sepuluh calon pelanggan mengenai atribut-atribut yang mereka jadikan sebagai bahan pertimbangan dalam memilih lembaga pelatihan dan sertifikasi. Kemudian atribut yang berasal dari VoC dan studi literatur pada penelitian terdahulu digabungkan dan dikelompokkan ke dalam lima variabel Eduqual menurut Mahapatra dan Khan dalam Kumaran dan Anbazhagan [8] dan Jain, Sinha, dan Sahney [9], yaitu learning outcomes, responsiveness, infrastructure, personality development, dan academics. Setelah dikelompokkan, atribut-atribut tersebut direduksi dengan menggunakan analisis faktor untuk mendapatkan atribut-atribut yang dianggap penting dan berpengaruh dalam hal penilaian terhadap lembaga pelatihan dan sertifikasi. Merek-merek lembaga pelatihan dan sertifikasi khususnya dalam hal ini yang bergerak di bidang multimedia dan atribut-atribut yang telah direduksi menjadi input pada analisis lanjutan dengan menggunakan metode MDS yang menghasilkan perceptual map. Perceptual map memvisualisasikan kesesuaian antara merek-merek lembaga pelatihan dan sertifikasi dengan atributatribut yang ada. Rekomendasi yang dilakukan bedasarkan pada perceptual map yang dihasilkan dan memiliki bertujuan untuk memperbaiki citra TPCC melalui program studi CMP dalam benak masyarakat. Model konseptual pada penelitian ini dapat dilihat pada Gambar 1.

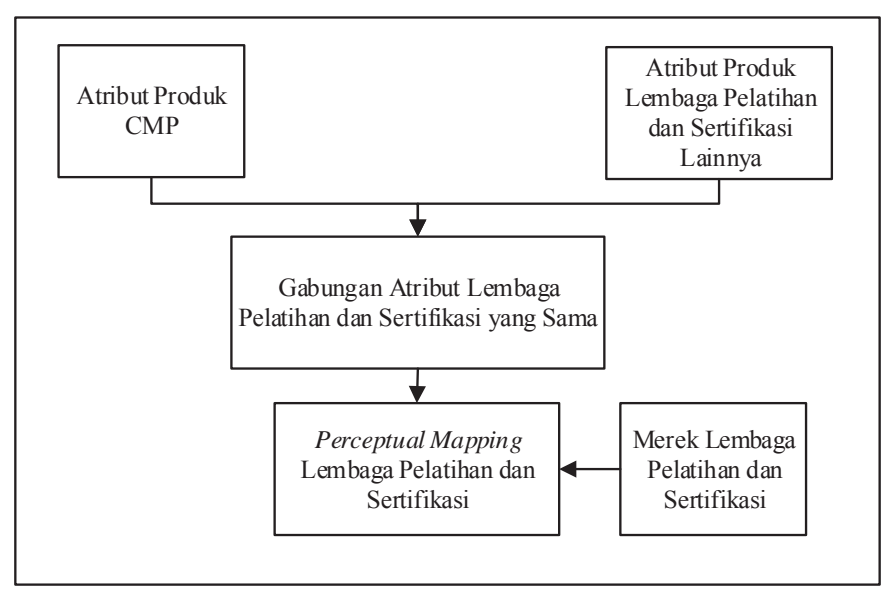

Gambar 1 Model Konseptual

\section{HASIL DAN PEMBAHASAN}

A. Pengolahan Kuesioner Pendahuluan

Atribut yang telah diidentifikasi melalui wawancara dan studi literatur pada penelitian terdahulu menjadi input pada kuesioner pendahuluan. Terdapat delapan belas atribut yang dinilai responden mengenai tingkat kepentingannya terhadap lembaga pelatihan dan sertifikasi di bidang multimedia. Keluaran atau output dari kuesioner pendahuluan merupakan atribut-atribut yang telah direduksi dengan menggunakan analisis faktor sehingga menghasilkan tiga belas atribut (Tabel 
I). Atribut-atribut tersebut merupakan atribut yang responden anggap penting dalam menilai suatu lembaga pelatihan dan sertifikasi.

TABEL I

ATRIBUT-ATRIBUT HASIL ANALISIS FAKTOR

\begin{tabular}{|c|c|c|}
\hline Variabel & $\begin{array}{c}\text { Atribut Produk Pelatihan dan } \\
\text { Sertifikasi }\end{array}$ & $\begin{array}{c}\text { Kode } \\
\text { Atribut }\end{array}$ \\
\hline \multirow{3}{*}{$\begin{array}{l}\text { Learning } \\
\text { Outcomes }\end{array}$} & $\begin{array}{l}\text { Kemudahan dalam mendapatkan } \\
\text { pekerjaan setelah lulus dalam bidang } \\
\text { multimedia }\end{array}$ & LO1 \\
\hline & $\begin{array}{l}\text { Lulusan yang berkualitas (memiliki } \\
\text { pengakuan sertifikasi nasional/ } \\
\text { internasional) }\end{array}$ & LO2 \\
\hline & $\begin{array}{l}\text { Lulusan memiliki kemampuan yang } \\
\text { memenuhi job requirement dalam } \\
\text { bidang multimedia }\end{array}$ & LO3 \\
\hline \multirow{4}{*}{ Responsiveness } & $\begin{array}{l}\text { Segala bentuk keluhan mahasiswa } \\
\text { direspon dengan cepat oleh staff } \\
\text { tenaga pendukung }\end{array}$ & $\mathrm{R} 1$ \\
\hline & $\begin{array}{l}\text { Informasi yang berhubungan dengan } \\
\text { kegiatan belajar mengajar disampaikan } \\
\text { dengan jelas }\end{array}$ & $\mathrm{R} 2$ \\
\hline & $\begin{array}{l}\text { Kemudahan mahasiswa dalam } \\
\text { menyampaikan keluhan kepada bagian } \\
\text { staff pendukung }\end{array}$ & $\mathrm{R} 3$ \\
\hline & $\begin{array}{l}\text { Kemudahan mahasiswa dalam } \\
\text { melakukan konsultasi kepada staff } \\
\text { pengajar }\end{array}$ & R5 \\
\hline \multirow[t]{2}{*}{ Infrastructures } & $\begin{array}{l}\text { Kelengkapan fasilitas akademik yang } \\
\text { mendukung kegiatan belajar mengajar } \\
\text { khususnya di bidang multimedia } \\
\text { (contoh: laboratorium, ruang kelas, } \\
\text { komputer, dan lain-lain) }\end{array}$ & I1 \\
\hline & $\begin{array}{l}\text { Kelengkapan fasilitas non-akademik } \\
\text { yang disediakan (contoh: lapangan } \\
\text { olahraga, atm, tempat parkir dan lain- } \\
\text { lain) }\end{array}$ & $\mathrm{I} 2$ \\
\hline \multirow[b]{2}{*}{$\begin{array}{l}\text { Personality } \\
\text { Development }\end{array}$} & $\begin{array}{l}\text { Pengakuan atas mahasiswa yang } \\
\text { berprestasi (contoh: beasiswa, } \\
\text { sertifikat/ piagam) }\end{array}$ & PD1 \\
\hline & $\begin{array}{l}\text { Kegiatan pembelajaran yang } \\
\text { disediakan sangat mendukung untuk } \\
\text { meningkatkan softskills yang dimiliki } \\
\text { oleh mahasiswa (contoh: melalui } \\
\text { kegiatan lab dapat meningkatkan } \\
\text { softskills mahasiswa) }\end{array}$ & PD2 \\
\hline \multirow{2}{*}{ Academics } & $\begin{array}{l}\text { Materi pelatihan yang diberikan sudah } \\
\text { sesuai dengan kebutuhan industri di } \\
\text { bidang multimedia }\end{array}$ & A1 \\
\hline & $\begin{array}{l}\text { Kegiatan pembelajaran yang bervariasi } \\
\text { (contoh: kuliah umum, seminar, } \\
\text { magang, dan lain-lain) }\end{array}$ & A5 \\
\hline
\end{tabular}

B. Pengolahan Kuesioner Lanjutan

Atribut hasil dari analisis faktor menjadi input pada kuesioner lanjutan. Pada kuesioner lanjutan, responden diminta untuk memberikan penilaian berupa ranking dari delapan merek lembaga pelatihan dan sertifikasi bedasarkan tiap atribut yang ada. Semakin kecil ranking yang diberikan oleh responden pada suatu merek lembaga pelatihan dan sertifikasi bedasarkan atribut yang ada, maka semakin sesuai merek lembaga pelatihan dan sertifikasi tersebut dengan atribut yang ada menurut persepsi responden, begitupun sebaliknya. Penilaian yang diberikan oleh responden bedasarkan persepsi mereka mengenai kedelapan merek lembaga dan pelatihan bedasarkan informasi yang telah mereka miliki. Pengolahan data pada kuesioner lanjutan dilakukan dengan metode MDS. Hasil dari pengolahan data dengan menggunakan metode MDS menghasilkan perceptual map yang dapat dilihat pada Gambar 2 .

\section{Analisis Data}

Langkah selanjutnya setelah mendapatkan hasil perceptual map dan koordinat-koordinat yang ada di dalamnya adalah melakukan perhitungan jarak euclidean sehingga dapat diidentifikasi pesaing terdekat TPCC melalui program studi CMP dan posisi merek-merek lembaga pelatihan dan sertifikasi di bidang multimedia lainnya

\section{Peta Persaingan Lembaga Pelatihan dan Sertifikasi}

Bedasarkan hasil dari perhitungan jarak euclidean dan perceptual map, dapat diketahui pesaing terdekat dari TPCC adalah Binus Center. TPCC dan Binus berada di wilayah persaingan yang sama. Kesamaan dari kedua lembaga pelatihan dan sertifikasi tersebut adalah memiliki kualitas sertifikasi yang diberikan kepada lulusannya mengacu pada tingkat internasional. Oleh karena itu, kedua lembaga pelatihan dan sertifikasi tersebut berada pada wilayah persaingan yang sama. Peta persaingan lembaga pelatihan dan sertifikasi dapat dilihat pada Gambar 3.

E. Analisis Keunggulan Atribut TPCC melalui Program Studi CMP

Perhitungan jarak euclidean juga dapat memberikan informasi mengenai atribut-atribut yang menjadi keunggulan dari TPCC melalui program studinya CMP. Atribut yang menjadi keunggulan tersebut dapat diketahui melalui peringkat pertama yang diperoleh TPCC pada setiap atribut lembaga pelatihan dan sertifikasi bedasarkan hasil perhitungan jarak euclidean yang telah dilakukan sebelumnya. Tabel II menunjukkan peringkat dan besar jarak euclidean TPCC melalui program studi CMP pada setiap atribut yang digunakan pada perceptual map.

Bedasarkan Tabel II atribut yang menjadi keunggulan TPCC melalui produknya CMP dalam pasar persaingan lembaga pelatihan dan sertifikasi dibidang multimedia, yaitu LO1, LO3, R2, R3, I2, dan PD1.

TABEL II

PERINGKAT DAN BESAR JARAK EUCLIDEAN TPCC PADA SETIAP ATRIBUT

\begin{tabular}{|c|c|c|c|}
\hline Variabel & $\begin{array}{c}\text { Kode } \\
\text { Atribut }\end{array}$ & $\begin{array}{c}\text { Euclidean } \\
\text { Distance }\end{array}$ & Peringkat \\
\hline \multirow{2}{*}{$\begin{array}{c}\text { Learning } \\
\text { Outcomes }\end{array}$} & LO1 & $\mathbf{0 , 1 6 9 4}$ & $\mathbf{1}$ \\
\cline { 2 - 4 } & LO2 & 0,0272 & 2 \\
\cline { 2 - 4 } & LO3 & $\mathbf{0 , 1 4 6 6}$ & $\mathbf{1}$ \\
\hline \multirow{3}{*}{ Responsiveness } & R1 & 0,0405 & 2 \\
\cline { 2 - 4 } & $\mathbf{R 2}$ & $\mathbf{0 , 2 9 9 0}$ & $\mathbf{1}$ \\
\cline { 2 - 4 } & $\mathbf{R 3}$ & $\mathbf{0 , 1 6 9 5}$ & $\mathbf{1}$ \\
\cline { 2 - 4 } & $\mathrm{R} 5$ & 0,0397 & 2 \\
\hline \multirow{2}{*}{ Infrastructures } & $\mathrm{I}$ & 0,0397 & 2 \\
\cline { 2 - 4 } & $\mathbf{I}$ & $\mathbf{0 , 0 0 4 0}$ & $\mathbf{1}$ \\
\hline \multirow{2}{*}{$\begin{array}{c}\text { Personality } \\
\text { Development }\end{array}$} & $\mathbf{P D 1}$ & $\mathbf{1 , 1 3 4 0}$ & $\mathbf{1}$ \\
\cline { 2 - 4 } & $\mathrm{PD} 2$ & 0,0188 & 2 \\
\hline \multirow{2}{*}{ Academics } & $\mathrm{A} 1$ & 0,0179 & 2 \\
\cline { 2 - 4 } & $\mathrm{A} 5$ & 1,2807 & 4 \\
\hline
\end{tabular}



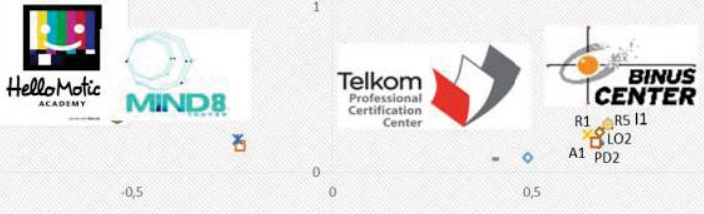

$103 \mathrm{CL}^{\mathrm{LO}}$

Wabnstud dio.com

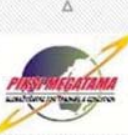

$\stackrel{x}{\mathrm{R} 2}$

$\overline{P D 1}$

\section{MiNTER LUISA}

3
Adhibina

Komputer

Wilayah A

$\Delta^{-1}$

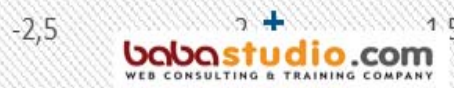

Wilayah C

\section{Wilayah B}

2

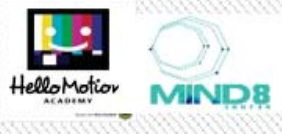

*

$-0,5$

0

0.

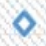

0,5

1

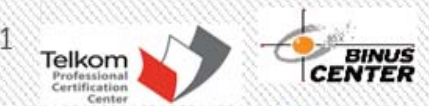

$\times$
$-1$

$-2$

$-3$ 


\section{F. Dasar Rekomendasi}

Atribut yang menjadi kelemahan TPCC dapat diketahui dengan membandingkan nilai jarak euclidean yang dimiliki oleh TPCC melalui program studi CMP dengan pesaing terdekatnya, yaitu Binus Center. Perbandingan nilai jarak euclidean TPCC dengan Binus Center dapat dilihat pada Tabel III. Semakin besar nilai negatif yang dihasilkan pada perbandingan kedua lembaga tersebut maka semakin lemah atribut tersebut terhadap TPCC. Bedasarkan perhitungan perbandingan jarak euclidean tersebut dapat diketahui bahwa terdapat tujuh atribut yang menjadi kelemahan TPCC.

TABEL III

PERBANDINGAN NILAI JARAK EUCLIDEAN TPCC DENGAN BINUS CENTER

\begin{tabular}{|c|c|c|c|c|}
\hline Variabel & $\begin{array}{c}\text { Kode } \\
\text { Atribut }\end{array}$ & $\begin{array}{c}\text { Euclidean } \\
\text { Distance } \\
\text { TPCC }\end{array}$ & $\begin{array}{c}\text { Euclidean } \\
\text { Distance } \\
\text { Binus } \\
\text { Center }\end{array}$ & $\begin{array}{c}\text { Selisih Nilai } \\
\text { Euclidean } \\
\text { Distance }\end{array}$ \\
\hline \multirow{3}{*}{$\begin{array}{l}\text { Learning } \\
\text { Outcomes }\end{array}$} & LO1 & 0,1694 & 0,2329 & 0,0635 \\
\hline & LO2 & $\mathbf{0 , 0 2 7 2}$ & 0,0005 & $-0,0267$ \\
\hline & LO3 & 0,1466 & 0,2076 & 0,0610 \\
\hline \multirow{4}{*}{ Responsiveness } & R1 & 0,0405 & 0,0036 & $-0,0369$ \\
\hline & R2 & 0,2990 & 0,4254 & 0,1264 \\
\hline & R3 & 0,1695 & 0,2330 & 0,0635 \\
\hline & R5 & $\mathbf{0 , 0 3 9 7}$ & 0,0034 & $-0,0364$ \\
\hline \multirow{2}{*}{ Infrastructures } & I1 & $\mathbf{0 , 0 3 9 7}$ & 0,0034 & $-0,0364$ \\
\hline & $\mathrm{I} 2$ & 0,0040 & 0,0389 & 0,0349 \\
\hline \multirow{2}{*}{$\begin{array}{c}\text { Personality } \\
\text { Development }\end{array}$} & PD1 & 1,1340 & 1,3910 & 0,2570 \\
\hline & PD2 & $\mathbf{0 , 0 1 8 8}$ & $\mathbf{0 , 0 0 1 7}$ & $-0,0172$ \\
\hline \multirow{2}{*}{ Academics } & A1 & 0,0179 & 0,0014 & $-0,0165$ \\
\hline & A5 & 1,2807 & 1,1732 & $-0,1075$ \\
\hline
\end{tabular}

Rekomendasi didasarkan pada atribut-atribut yang menjadi kelemahan TPCC, namun atribut tersebut mempengaruhi dari tujuan TPCC ingin dipandang seperti apa di tengah masyarakat. Tujuan dari TPCC dapat dilihat melalui visi yang mereka miliki, yaitu "To become a leading internationally qualified and recognized Professional Certification Body and Center of Competence Development in the region". Mengacu pada visi tersebut dapat diketahui bahwa TPCC ingin dipandang sebagai lembaga pelatihan dan sertifikasi yang diakui secara internasional. Berdasarkan tujuan TPCC tersebut dari tujuh atribut yang menjadi kelemahan TPCC terdapat enam atribut yang menunjang tercapainya tujuan TPCC tersebut, sehingga jumlah atribut yang akan direkomendasikan untuk dilakukan perbaikan ada enam atribut. Tujuan dari dilakukannya rekomendasi perbaikan agar positioning TPCC dapat tersampaikan secara jelas dan tepat di tengah persepsi masyarakat. Atribut-atribut yang akan direkomendasikan untuk dilakukan perbaikan dapat dilihat pada Tabel IV.

\section{G. Rekomendasi Akhir}

Selanjutnya setelah mengetahui atribut apa saja yang direkomendasikan untuk diperbaiki, dilakukan perancangan rekomendasi terhadap keenam atribut yang lemah tersebut. Rekomendasi yang diusulkan untuk dilakukan pihak TPCC dapat dilihat pada Tabel V. Langkah selanjutnya, yaitu rekomendasi-rekomendasi tersebut diajukan kepada pihak TPCC untuk mengetahui masukan pendapat dan pertimbangan dalam melakukan perbaikan yang telah diusulkan agar dilakukan oleh pihak TPCC. Rekomendasi yang diusulkan pada telah disetujui oleh pihak TPCC dan beberapa rekomendasi yang telah disetujui, namun diperlukan analisis perancangan program lebih lanjut agar rekomendasi tersebut dapat dilaksanakan.

TABEL IV

ATRIBUT TPCC YANG AKAN DIPERBAIKI

\begin{tabular}{|c|l|c|}
\hline $\begin{array}{c}\text { Kode } \\
\text { Atribut }\end{array}$ & \multicolumn{1}{|c|}{ Atribut } & Dimensi \\
\hline LO2 & $\begin{array}{l}\text { Lulusan yang berkualitas (memiliki pengakuan } \\
\text { sertifikasi nasional/ internasional) }\end{array}$ & $\begin{array}{c}\text { Education } \\
\text { Quality }\end{array}$ \\
\hline R5 & $\begin{array}{l}\text { Kemudahan mahasiswa dalam melakukan } \\
\text { konsultasi kepada staff pengajar }\end{array}$ & $\begin{array}{c}\text { Education } \\
\text { Quality }\end{array}$ \\
\hline I1 & $\begin{array}{l}\text { Kelengkapan fasilitas akademik yang } \\
\text { mendukung kegiatan belajar mengajar } \\
\text { khususnya di bidang multimedia (contoh: } \\
\text { laboratorium, ruang kelas, komputer, dll) }\end{array}$ & $\begin{array}{c}\text { Education } \\
\text { Quality }\end{array}$ \\
\hline PD2 & $\begin{array}{l}\text { Kegiatan pembelajaran yang disediakan sangat } \\
\text { mendukung untuk meningkatkan softskills } \\
\text { yang dimiliki oleh mahasiswa (contoh: melalui } \\
\text { kegiatan lab dapat meningkatkan softskills } \\
\text { mahasiswa) }\end{array}$ & $\begin{array}{c}\text { Education } \\
\text { Quality }\end{array}$ \\
\hline A1 & $\begin{array}{l}\text { Materi pelatihan yang diberikan sudah sesuai } \\
\text { dengan kebutuhan industri di bidang } \\
\text { multimedia }\end{array}$ & $\begin{array}{c}\text { Education } \\
\text { Quality }\end{array}$ \\
\hline A5 & $\begin{array}{l}\text { Kegiatan pembelajaran yang bervariasi } \\
\text { (contoh: kuliah umum, seminar, magang, dll) }\end{array}$ & Content \\
\hline
\end{tabular}

TABEL V

REKOMENDASI PERBAIKAN ATRIBUT TPCC

\begin{tabular}{|c|c|c|}
\hline No. & Atribut & Rekomendasi \\
\hline 1 & $\begin{array}{l}\text { Lulusan yang berkualitas } \\
\text { (memiliki pengakuan } \\
\text { sertifikasi nasional/ } \\
\text { internasional) }\end{array}$ & $\begin{array}{l}\text { Sertifikasi tingkat internasional } \\
\text { dikomunikasi secara jelas kepada } \\
\text { konsumen, agar dapat menjadi daya } \\
\text { tarik dibandingkan dengan kompetitor } \\
\text { (contoh: melalui sebuah tagline) }\end{array}$ \\
\hline 2 & $\begin{array}{l}\text { Kemudahan mahasiswa } \\
\text { dalam melakukan } \\
\text { konsultasi kepada staff } \\
\text { pengajar }\end{array}$ & $\begin{array}{l}\text { Menyediakan fasilitas program } \\
\text { konsultasi khusus yang dapat } \\
\text { dilakukan oleh mahasiswa kepada } \\
\text { staff pengajar mengenai hal-hal yang } \\
\text { berhubungan dengan pembelajaran }\end{array}$ \\
\hline 3 & $\begin{array}{l}\text { Kelengkapan fasilitas } \\
\text { akademik yang } \\
\text { mendukung kegiatan } \\
\text { belajar mengajar } \\
\text { khususnya di bidang } \\
\text { multimedia (contoh: } \\
\text { laboratorium, ruang } \\
\text { kelas, komputer, dan } \\
\text { lain-lain) }\end{array}$ & $\begin{array}{l}\text { Melengkapi fasilitas presentasi di } \\
\text { setiap kelasnya (proyektor, speaker). } \\
\text { Meningkatkan kapasitas bandwith } \\
\text { minimal } 5 \text { (lima) Kbps/ mahasiswa }\end{array}$ \\
\hline 4 & $\begin{array}{l}\text { Kegiatan pembelajaran } \\
\text { yang disediakan sangat } \\
\text { mendukung untuk } \\
\text { meningkatkan softskills } \\
\text { yang dimiliki oleh } \\
\text { mahasiswa (contoh: } \\
\text { melalui kegiatan lab } \\
\text { dapat meningkatkan } \\
\text { softskills mahasiswa) }\end{array}$ & $\begin{array}{l}\text { Membuat beberapa program kegiatan } \\
\text { mahasiswa di luar kegiatan akademik } \\
\text { untuk mengasah softskill mereka } \\
\text { (contoh: membuat suatu kegiatan } \\
\text { kepanitiaan, komunitas yang } \\
\text { berhubungan dengan bidang } \\
\text { multimedia) yang diakui oleh TPCC }\end{array}$ \\
\hline 5 & $\begin{array}{l}\text { Materi pelatihan yang } \\
\text { diberikan sudah sesuai } \\
\text { dengan kebutuhan } \\
\text { industri di bidang } \\
\text { multimedia }\end{array}$ & $\begin{array}{l}\text { Bekerjasama dengan perusahaan } \\
\text { terkait khususnya di bidang } \\
\text { multimedia dalam hal penyusunan } \\
\text { konten materi pelatihan yang } \\
\text { dibutuhkan }\end{array}$ \\
\hline 6 & $\begin{array}{l}\text { Kegiatan pembelajaran } \\
\text { yang bervariasi (contoh: } \\
\text { kuliah umum, seminar, } \\
\text { magang, dan lain-lain) }\end{array}$ & $\begin{array}{l}\text { Menambah variasi kegiatan } \\
\text { pembelajaran seperti kuliah umum } \\
\text { yang mengundang praktisi di bidang } \\
\text { multimedia, company visit ke } \\
\text { perusahaan, dll. }\end{array}$ \\
\hline
\end{tabular}




\section{KESIMPULAN}

Bedasarkan penelitian yang telah dilakukan terdapat tiga belas atribut yang akan digunakan pada perceptual map untuk mengetahui posisi dari kedelapan merek lembaga pelatihan dan sertifikasi di bidang multimedia. Atribut-atribut tersebut dikelompokkan dalam lima variabel, yaitu learning outcomes, responsiveness, infrastructures, personality development, dan academics. Pada perceptual map yang ada, diketahui bahwa pesaing terdekat TPCC melalui program studi CMP adalah Binus Center. Hal ini karena pada perceptual map kedua merek lembaga pelatihan dan sertifikasi tersebut berada dalam satu wilayah persaingan yang sama. Kesamaan yang dimiliki dari kedua merek tersebut adalah kualitas dari sertifikasi yang mereka berikan mengacu pada tingkat internasional.. Rekomendasi perbaikan yang diusulkan didasarkan pada kelemahan atribut yang dimiliki oleh TPCC namun atribut tersebut akan menunjang tujuan yang dimiliki oleh TPCC. Sehingga terdapat enam atribut yang akan direkomendasikan untuk dilakukan perbaikan. Rekomendasi yang diusulkan untuk dilakukan oleh TPCC yaitu, sertifikasi tingkat internasional dikomunikasi secara jelas kepada konsumen, agar dapat menjadi daya tarik dibandingkan dengan kompetitor (contoh: melalui sebuah tagline), menyediakan fasilitas program konsultasi khusus yang dapat dilakukan oleh mahasiswa kepada staff pengajar mengenai hal-hal yang berhubungan dengan pembelajaran, melengkapi fasilitas presentasi di setiap kelasnya (proyektor, speaker), meningkatkan kapasitas bandwith minimal $5 \mathrm{Kbps} /$ mahasiswa, membuat beberapa program kegiatan mahasiswa di luar kegiatan akademik untuk mengasah softskill mereka (contoh: membuat suatu kegiatan kepanitiaan, komunitas yang berhubungan dengan bidang multimedia) yang diakui oleh TPCC, bekerjasama dengan perusahaan terkait khususnya di bidang multimedia dalam hal penyusunan konten materi pelatihan yang dibutuhkan, dan menambah variasi kegiatan pembelajaran seperti seminar/ kuliah umum yang mengundang para praktisi/ expert di bidang multimedia, company visit ke perusahaan yang melibatkan kemampuan multimedia.

\section{DAFTAR PUSTAKA}

[1] Badan Nasional Sertifikasi Profesi, Statistik Perkembangan LSP, http://www.bnsp.go.id/lsp/statistik_bnsp.html., diakses: Desember 2015].

[2] Kotler, Philip., Keller, Kevin Lane., Manajemen Pemasaran, Jilid 1, Diterjemahkan Oleh: Bob Sabran, Jakarta: Erlangga, Edisi ke 13, 2009.

[3] Malhotra, Naresh K., Riset Pemasaran, Jilid 2, Edisi keempat, Diterjemahkan Oleh: Soleh Rusyadi Maryam, Jakarta: PT Indeks, Edisi Keempat, 2010.

[4] Simamora, Bilson., Analisis Multivariat Pemasaran, Jakarta: PT Gramedia Pustaka Utama, 2005.

[5] Mustaniroh, Siti Asmaul., Mulyarto, Aunur Rofiq., Nurkhasanah, Siti., Analisis Positioning Keripik Kentang dengan Pendekatan Metode Multi Dimensional Scalling di Kota Batu, Agrointek, Volume 5, 2011, pp. 98-106.

[6] Badrian, Fikri Akhmad., Analisis Positioning Layanan Televisi Berbayar Groovia TV Bedasarkan Perceptual Mapping dengan Metode Multi Dimensional Scalling di Kota Jakarta, Skripsi. Program Sarjana Teknik Industri, Universitas Telkom, 2013.

[7] Altivira, Raisa., Analisis Positioning Menu Breakfast Restoran Waralaba Siap Saji Bedasarkan Persepsi Konsumen di Kota Bandung Tahun 2014 (Studi pada: Kentucky Fried Chicken, McDonald's, Pizza Hut, dan Dunkin'Donuts), Skripsi. Program Sarjana Manajemen Bisnis Telekomunikasi dan Informatika. Universitas Telkom, 2014.

[8] Kumaran, P.Senthil., Anbazhagan, B., A Study on Quality in Higher Education: Student's Perspective, Journal for Bloomers of Research Vol 3 No.2, 2011, pp. 222-226.

[9] Jain, Rain., Sinha, Gautam., Sahney, Sangeeta., Conceptualizing Service Quality in Higher Education, Asian Journal on Quality, Vol.12 No.3, 2011, pp. 296314. 